\title{
The role of reelin in the development and evolution of the cerebral cortex
}

\author{
F. Tissir ${ }^{1}$, \\ C. Lambert de Rouvroit ${ }^{2}$ \\ and A.M. Goffinet ${ }^{1}$
}

\author{
1Developmental Genetics Unit, GEDE 7382, \\ University of Louvain Medical School, Brussels, Belgium \\ ${ }^{2}$ Developmental Neurobiology Unit 2853, \\ University of Namur Medical School, Namur, Belgium
}

\begin{abstract}
Correspondence
A.M. Goffinet

Developmental Genetics Unit

GEDE 7382

University of Louvain Medical School

Avenue Mounier, 73

B1200 Brussels

Belgium

Fax: $+32-2-764-7430$

E-mail: andre.goffinet@gede.ucl.ac.be

Presented at the IV International UNESCO Symposium on "What the Developing Cerebral Cortex Tells About the Adult Cortex (and Vice Versa)", Rio de Janeiro, RJ, Brazil, December 3-7, 2001.
\end{abstract}

Received July 12, 2002 Accepted September 18, 2002

\begin{abstract}
Reelin is an extracellular matrix protein that is defective in reeler mutant mice and plays a key role in the organization of architectonic patterns, particularly in the cerebral cortex. In mammals, a "reelin signal" is activated when reelin, secreted by Cajal-Retzius neurons, binds to receptors of the lipoprotein receptor family on the surface of cortical plate cells, and triggers Dab1 phosphorylation. As reelin is a key component of cortical development in mammals, comparative embryological studies of reelin expression were carried out during cortical development in non-mammalian amniotes (turtles, squamates, birds and crocodiles) in order to assess the putative role of reelin during cortical evolution. The data show that reelin is present in the cortical marginal zone in all amniotes, and suggest that reelin has been implicated in the evolution of the radial organization of the cortical plate in the synapsid lineage leading from stem amniotes to mammals, as well as in the lineage leading to squamates, thus providing an example of homoplastic evolution (evolutionary convergence). The mechanisms by which reelin instructs radial cortical organization in these two lineages seem different: in the synapsid lineage, a drastic amplification of reelin production occurred in Cajal-Retzius cells, whereas in squamates, in addition to reelin-secreting cells in the marginal zone, a second layer of reelin-producing cells developed in the subcortex. Altogether, our results suggest that the reelin-signaling pathway has played a significant role in shaping the evolution of cortical development.
\end{abstract}

\section{Introduction}

The role of the reelin-signaling pathway is well established, and there is some evidence that this pathway also played a key role during the evolution of the cerebral cortex from stem amniotes to mammals, providing an interesting example of an Evo-Devo approach of cortical development $(1,2)$. The arguments for this view will be introduced in
Key words

- Reeler

- Dab1

- VLDLR

- ApoER2

.................... two parts. First, we will summarize our current knowledge of the reelin-signaling pathway and its role during normal cortical development, and we will then overview comparative embryological data that support a role of reelin during cortical evolution.

\section{Reelin and cortical development}

When the embryonic telencephalon is 
compared in normal mouse and reeler (reelindeficient) mice, the most evident difference is at the level of the cortical plate, which is dense and radially organized in the normal mouse, but really disordered in reeler mice $(3,4)$. Normal cortical development begins with a neuroepithelium, which lasts until about E11 in the mouse and is followed by a very transient stage, called preplate, when the first postmitotic neurons migrate to the periphery of the telencephalon and form a loose, horizontal network.

The next stage is the appearance of the cortical plate, which occurs in mice at E13E14, and in man around the 7th or 8th gestational week. In normal mice and all mammals as far as we know, neurons are generated close to the ventricle. Most glutamatergic cells migrate radially from the ventricular zone, along radial cells, whereas most GABAergic neurons are generated in the ganglionic eminences, the primordium of the striatum, and gain access to the cortex by tangential migration $(5,6)$. At the end of migration, cortical neurons form a dense, radially organized structure named cortical plate. The cortical plate is very dense in normal animals and this compact cell layer splits the preplate into two components. Some preplate derivatives settle externally in the marginal zone, whereas others settle below the cortical plate and form the sub(cortical) plate. In reeler mice and mice homozygous for mutations in members of the reelin pathway, neurons are generated at the normal time, at the normal place and in normal numbers. They first migrate normally, but something goes wrong at the end of migration. The neurons of the reeler mouse cortical plate differentiate normally, they even connect normally. However, instead of assuming a radial architectonic organization, they develop an abnormal, distorted orientation.

The gene that is affected in reeler mice was named reelin. It encodes a large protein of about 400 to $450 \mathrm{kDa}$. The protein has a signal peptide. It is an extracellular protein, with an N-terminal region similar to another extracellular protein named spondin. This is followed by a region that does not resemble anything else, and then by eight reelin repeats. Each of these reelin repeats is quite large, 300-350 amino acids, and has an EGF motif at the center. The protein ends with a highly basic $\mathrm{C}$ terminus. There is no transmembrane region, so this is a purely extracellular protein that probably is incorporated into the extracellular matrix, although at this stage we do not know with what components in the matrix it interacts.

As the morphological defect in reeler mice consists of a disorganization of the cortical plate, it was surprising when the gene was cloned to find out that it was not expressed in the cells that are abnormal in mutated animals. Instead, reelin is found, both using immunohistochemistry and in situ hybridization, in early marginal zone neurons that correspond to the Cajal-Retzius cells. A frequently made oversimplification should be noted: the marginal zone contains at that stage at least two types of neurons, namely subpial, large reelin-positive CajalRetzius neurons that extend their axons in the marginal zone, and other large, reelinnegative neurons located deeper in the marginal zone that probably pioneer the early corticofugal projections and will not be discussed further here (7).

A rather similar development occurs in all mammals, including humans (8). In the human cortex, a well-defined marginal zone and a laminarly organized cortical plate populated with radial cells are evident at 7 weeks. The same layers are defined as in mice, from the pial surface to the ventricle, namely marginal zone, cortical plate, subplate, intermediate zone, and subventricular and ventricular zone. Using an anti-reelin antibody, CajalRetzius cells are detected just below the pial surface, while the cortical plate is reelin negative. It should be noted, however, that reelin-positive neurons appear in the cortex 
at a later stage, around birth in rodents, and that they are different from Cajal-Retzius cells but probably belong to the contingent of GABAergic interneurons of the cortex.

Cajal-Retzius cells are among the earliest generated cortical neurons. They have features typical of neuronal cells, such as an axonal arbor and a dendritic tree, but they also have some atypical features, both morphological and physiological. For example, their axon potentials are relatively slower than those generated by other cortical cells. Morphologically, a unique characteristic is that Cajal-Retzius neurons come into direct contact with the basal lamina. Most cortical neurons never touch the basal lamina directly but are kept separated from it by glial end-feet. Cajal-Retzius neurons are an exception, as they send processes that insinuate between glial end-feet and adhere to the basal lamina. In humans, Cajal-Retzius neurons reach a highly elaborate organization and extend numerous radial branches to the pial surface. It is reasonable to suggest that these radial extensions reflect the focal adhesion to the basal lamina, and that this adhesion progressively gives rise to radial cytoplasmic extensions when the cell is progressively displaced during development from its immediate subpial location to a deeper level in the marginal zone.

In contrast to the preplate derivatives that form the early horizontal and loose network, the cells in the cortical plate are initially oblique but not horizontal, and then become rapidly organized in a strictly radial shape, with formation of the dense cortical plate that covers basically all cortical areas. Most cortical plate cells are bipolar, with a dendritic pole that ramifies towards the marginal zone and an inner pole from which the axon emerges radially and then, as it reaches the subplate and the border of the intermediate zone, turns at a right angle and runs tangentially in the future white matter en route towards the thalamus. Of course, at later developmental stages, corticofugal axons become directed at other subcortical targets. As discussed in more detail by others (5), it is most probable that the early corticofugal axons serve to guide later cortical projections as well as early afferent fibers from the thalamus, and that they also play a role in the guidance of migrating GABAergic cells from the medial ganglionic eminence to the cortex. With the appearance of a dense cortical plate, the early horizontal derivatives of the preplate become divided into two contingents. Some are displaced outward and settle in the marginal zone, whereas others are displaced at a deeper level and settle in the subplate.

As the cortical plate thickens with further cell migration, newly arriving cells pass through previously established layers of older neurons. As a consequence, the cortical ribbon is formed following an inside to outside gradient, with older cortical plate neurons being found in cortical layer VI and progressively younger neurons in layers V, IV, III and II.

In reelin-deficient and other animals with similar phenotypes, the preplate forms initially normally, but when cortical plate cells appear, they do not settle into a dense cortical plate as in normal animals. Instead, the reeler cortical plate is loosely populated with oblique rather than radial neurons and does not yield to a splitting of the preplate but rather to an outer displacement of the horizontal preplate cells "en bloc" in a subpial position. As cortical plate cells ramify their dendritic tree obliquely, cell bodies tend to invade the marginal zone, which becomes more and more crowded as development proceeds. As a consequence, the adult reeler cortex has no marginal zone (layer I). As the preplate is not split, the external tiers of the reeler cortex contain not only Cajal-Retzius neurons and other components of the normal marginal zone, but also cells that would be found in the subplate in normal animals. Another consequence of the cytoarchitectonic anomaly in reeler mice is that matura- 
tion of the cortical plate proceeds from outside to inside, instead of the inside-outside gradient that occurs in the normal cortical plate.

In case of defective reelin signaling, as mentioned above, the preplate is not split by the condensation of the cortical plate. As a consequence, things develop as if the radial orientation was not perceived by cells when they reach the inner aspect of the cortical plate, and young cells fail to migrate past previously established layers but instead settle at progressively deeper levels. Thus, in reelindeficient animals, cortical development proceeds from outside to inside and in adult animals the order of layers II to VI is grossly inverted. In addition, there is a wide dispersion of cortical layers that are clearly not sharply defined as they are in normal mammals.

Other mutations with an intermediate phenotype are worth mentioning. This phenotype occurs, for example, if the cyclindependent kinase 5 (Cdk5) gene or its activator co-factor $\mathrm{p} 35$ is mutated, or even better if both activator co-factors p35 and p39 are mutated $(9,10)$. In these animals, early development is almost normal, including preplate splitting and formation of an early cortical plate that is quite well organized radially. However, the next generation of neurons cannot migrate through this early cortical plate. It looks as if neurons were lacking migratory capacity when the distance they need to traverse increases. The mature phenotype is thus the following. There is a marginal zone, then a minute radial cortical plate, then a subplate, and finally a large stream of ectopic neurons that failed to achieve migration and settled between ventricular zones and the subplate. In this case, the gradient of cortical maturation is also "inverted", directed from outside to inside, even though the phenotype is different from that in reeler-like brains. This group of malformations shows that preplate splitting and the establishment of an inside to outside gradient are not necessarily linked.
After this summary of the cortical phenotype in various mutants, we will briefly introduce the other known members of the reelin-signaling pathway. Although cortical plate neurons do not produce any reelin (at least at early stages), they are the main targets of reelin. Reelin acts on target cells by binding to largely redundant receptors that are members of the LDL receptor family, namely the very-low-density lipoprotein receptor (VLDLR), and apolipoprotein E receptor type 2 (ApoER2) $(11,12)$. Single knockout mice for these two genes have a phenotype that is almost, although not entirely, normal. However, inactivation of both genes yields a reeler-like phenotype. The names are thus misleading because, although they can bind other proteins besides reelin and notably ApoE, obviously reelin is their most relevant functional ligand. VLDLR and ApoER 2 are characterized by the presence of seven or eight so-called LA repeats that are responsible for binding reelin. Like all the members of the lipoprotein receptor family they have a very short cytoplasmic region that cannot transmit a signal. The cytoplasmic tail contains an NPxY sequence that is a docking site for the phosphotyrosine-binding protein domain of an adapter, named disabled-1 or Dab1. Dab1 can be considered an extension of the cytoplasmic region of the receptors. Mice that are deficient in Dab1, by inactivation, by homologous recombination or by spontaneous mutation as in scrambler or yotari mutant mice, have exactly a reeler-like phenotype (13-15). Thus, the same phenotype is produced by inactivation of reelin, Dab1, and both VLDLR and ApoER2. Reelin binds to receptors directly, and this induces tyrosine phosphorylation of Dab1. The other partners of the signaling pathway are still unknown. How this reelin signal is translated in terms of neuronal phenotype similarly remains mysterious.

In summary, the provisional model is that Cajal-Retzius cells produce a gradient of reelin in the marginal zone and that, as soon 
as the tip of migrating cortical plate cells touches reelin, a signal generated by VLDLR/ ApoER2 and Dab1 phosphorylation is responsible for their radial organization. The mechanistic details are unknown.

\section{Reelin and cortical evolution}

Since reelin is critical to the normal development of the cortex, it could be that the modulation of reelin expression was important during the evolution of the cerebral cortex, particularly in the synapsid lineage that led from stem amniotes to mammals (16). In order to assess this idea, we examined the development of the embryonic cortical plate and studied reelin expression using in situ hybridization and immunohistochemistry in selected representatives of the main different phyla, i.e., turtles (anapsid lineage; 17), lizards (diapsid, lepidosaurian lineage; 18), crocodiles (diapsid, archosaurian lineage), and chick (19).

All living reptiles, birds and mammals are thought to have evolved from a common ancestor, the stem amniote (Figure 1). In other words, there is general consensus that the amniote egg evolved only once and that amniotes are monophyletic. All living reptiles and birds have a simple, mostly unilaminar cortex. The questions that we wanted to address are: i) How is this simple cortex organized at the embryonic stage of cortical plate formation? Is the cortical plate strictly radial and laminated as in normal mammalian embryos, or is it poorly defined as in reeler mutant mouse embryos? ii) What is the direction of the maturation gradient in this thin cortex? iii) Does the pattern of reelin expression differ from phylum to phylum and from mammals? As a corollary, do reptiles and birds have cells homologous to Cajal-Retzius cells?

Before we consider the development of the cortex, it is useful to present a simple overview of the evolution of the different phyla (Figure 1). Stem amniotes (formerly often named "stem reptiles") are thought to have evolved during the carboniferous. From this common ancestor, several lineages evolved, four of which led to the present reptiles, birds and mammals. The first lineage, the synapsids, separated early and evolved into the present marsupials and eutherian mammals. Another line, the anapsids, seems also to have separated early and gave rise to chelonians (turtles). The third branch, the lepidosaurs and eosuchians, contains the ancestors of the Rhynchocephalia, of which Spenodon punctatus (New Zealand's tuatara) is the only living representative, and the squamates (lizards and snakes). The fourth lineage, the archosaurs, evolved into dinosaurs and modern crocodilians (via thecodonts) and to birds (via saurischian dinosaurs). This summarized cladogram is schematically illustrated in Figure 1.

\section{Organization of the cortical plate}

The anatomy of the embryonic telencephalon of reptiles is different from that of mammals (Figure 2). First, as mentioned above, the cortical plate is mainly composed of a layer that is a few cells thick. The main

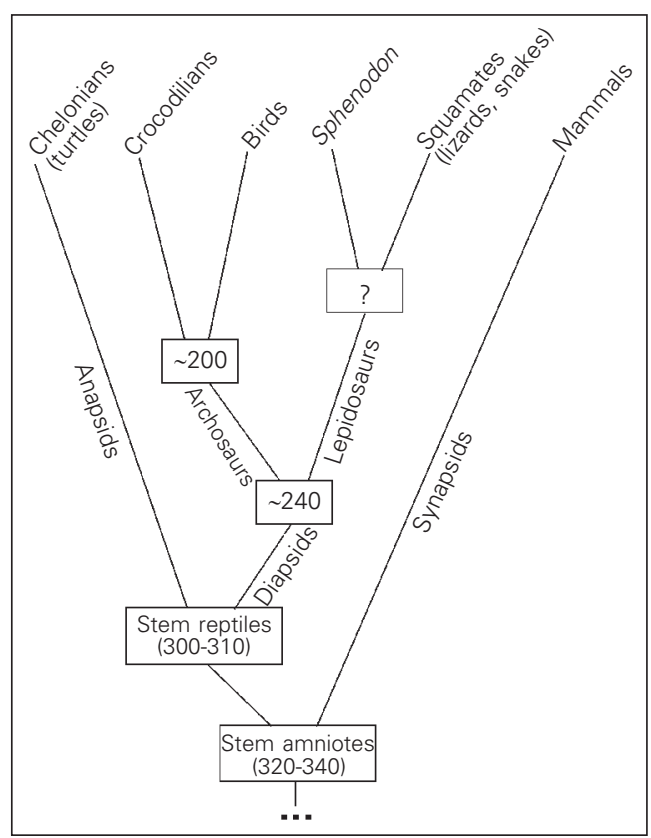

Figure 1. Simplified evolution of the amniote lineages that led to living mammals, reptiles and birds. Time in megayears. Adapted from Ref. 2. 
components of the cortex are the medial cortex, which is homologous to the mammalian hippocampal formation, the dorsal cortex (with some subdivisions in some species), homologous to the neocortex, and the lateral cortex, homologous to the pyriform cortex. In addition, reptiles and birds have a huge telencephalic compartment located ventrally to the lateral ventricle and dorsally to the striatum, named the dorsal ventricular ridge (DVR, formerly named hyperstriatum in birds). There has been (and still is) controversy about the mammalian structure that is homologous to the DVR, but the current trend is that the DVR regressed during mammalian evolution and is mainly represented by the claustrum. In this description, we focus on the cortical plate itself, and particularly the medial and dorsal cortex. Although stem amniotes are extinct and the organization of their embryonic brain will remain unknown, there is significant evidence that chelonians are, among living species, those most closely

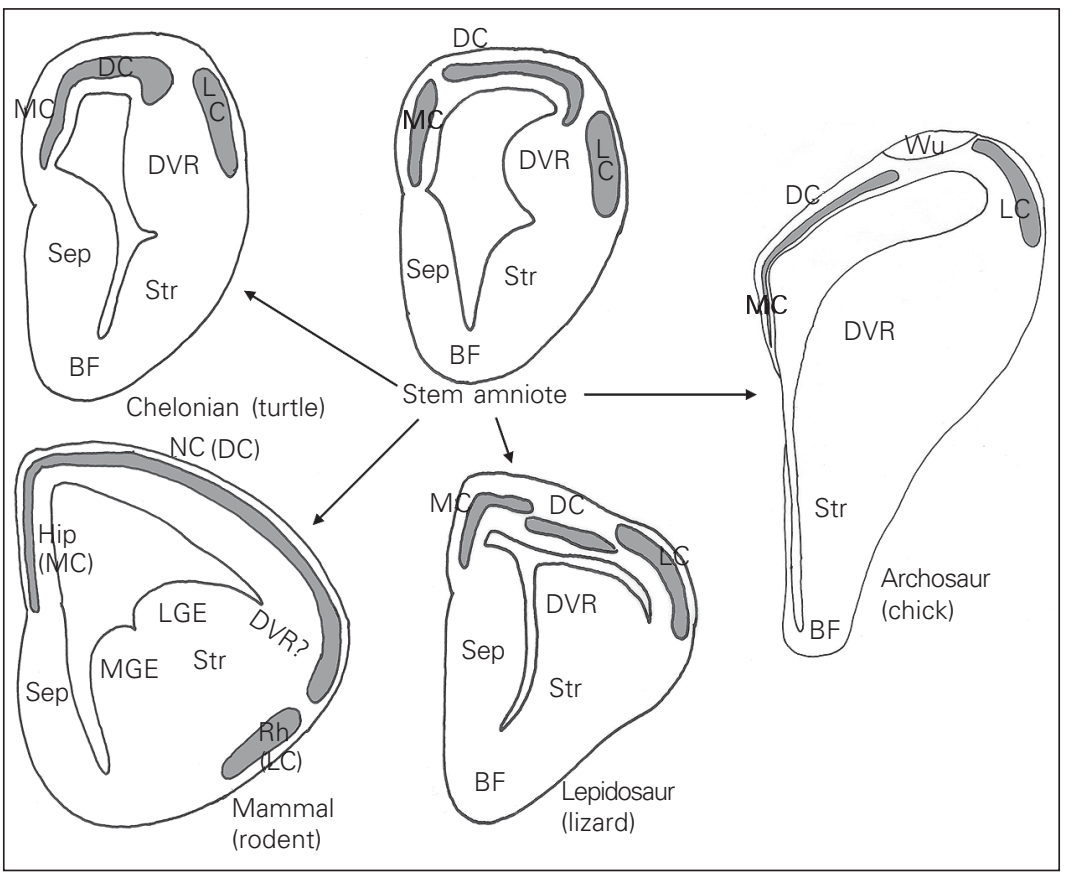

Figure 2. Overview of cortical organization in the different amniotes, with inference of an ancestral pattern in stem amniotes. BF: basal forebrain; DC: dorsal cortex; DVR: dorsal ventricular ridge; Hip: hippocampus; LC: lateral cortex; LGE: lateral ganglionic eminence; MC: medial cortex; MGE: medial ganglionic eminence; NC: neocortex; Rh: rhinencephalon (pyriform cortex); Sep: septum; Str: striatum; Wu: Wülst. Adapted from Ref. 2. related to stem amniotes and the present discussion will accept that premise.

In all species, early cortical development proceeds by following a common theme: neurons are generated in ventricular zones and migrate outward to form a cortex (16). The formation of a cortical plate is preceded by an early horizontal network or preplate. On the other hand, as soon as the cortical plate appears, important species differences are noted in terms of its architectonic organization. In turtle embryos (Figure 3), the cortical plate is loosely ordered, with poorly defined inner and outer borders. Although the cortical plate contains predominantly radially oriented cells, cortical plate neurons are not densely packed and their radial shape is highly variable. This rudimentary cortical plate organization stands in sharp contrast to that of squamates, particularly lacertilian lizards (Figure 3), in which the cortical plate is clearly defined, sharply separated from the marginal zone and the subplate, and populated with strictly radial neurons, in a pattern that is somewhat reminiscent of the mammalian one. The organization of the cortical plate in other reptiles can be described as intermediate between the rudimentary type found in chelonians and the elaborate type of lizards and mammals. For example, crocodiles have a well-populated cortical plate, but its borders are not clearly visible. The cortical plate of birds is similarly rather poorly defined and diminutive. In Sphenodon, there is an interesting sectorial variation: the medial cortex contains an elaborate cortical plate, similar to that of lizards, whereas the architectonics of the cortical plate in the dorsal cortex is more rudimentary, reminiscent of that of turtles. This large species difference in terms of embryonic cortical plate architectonics indicates that this complex structure is the product of an evolutionary process that occurred differently in different phyla, and that the elaborate pattern presently found in lizards and mammals reflects homoplasy (as opposed to a homolo- 
gous feature), the product of evolutionary convergence. If evolution bothers to build similar structures repeatedly, it usually means that these features are beneficial from an evolutionary standpoint (20). And indeed the radial organization of the embryonic cortical plate is required for the acquisition of a laminate cortex, as clearly demonstrated from observation in reeler-like phenotypes.

In summary, if turtles are considered to be related to stem amniotes, comparative studies of the embryonic cortical plate suggest that the radial cortical plate architectonics evolved differently in the various lineages to reach its more elaborate status in lizards and mammals. With respect to radial architectonic organization alone, the normal mouse and reeler cortical plate are reminiscent of the cortical plate of lizards and turtles, respectively.

\section{The gradient of cortical plate maturation}

In all mammals, marsupials included, the cortical plate develops following the insideoutside rule that we have outlined above. When the architectonics of the cortical plate is defective, as in reeler and similar mutant mice, this gradient is grossly inverted, directed from outside to inside. An obvious question concerns the histogenetic gradient in the reptilian cortical plate. Several years ago, we examined this question in turtle and lizard embryos by using in ovo injection of tritiated thymidine (21). Thymidine availability is sufficient to label all or at least most neurons that are generated after the injection, as demonstrated by the profuse labeling of some continuously proliferating epidermal or mesodermal cell types. The neurons that are not labeled are thus those that were generated prior to thymidine injection. Using this method, we could show that the maturation of the cortical plate is directed from outside to inside both in turtles and in lizards. Other species were not studied, but it is known from the literature that the gradient is also "outside-inside" in the chick cortical plate (22). There was a relative exception to the rule in that in the lizard medial cortex, no gradient could be defined and all neurons in that compact layer were either labeled or not labeled. A first conclusion from these observations is that the cortical plate of stem mammals most probably developed following an outside-inside gradient, and that the

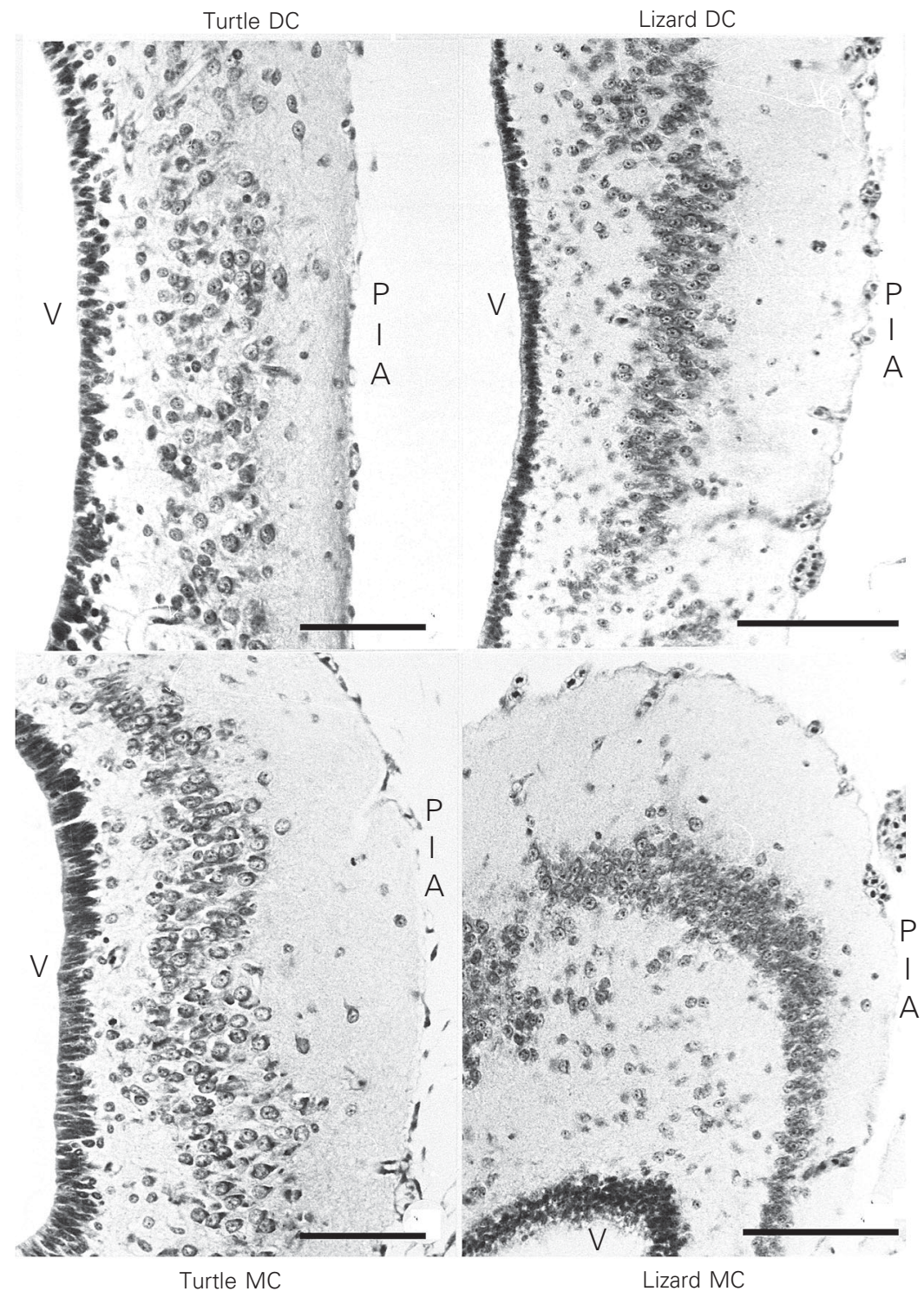

Figure 3. Comparison of embryonic cortical organization in turtles and lizards at the level of the medial (MC) and dorsal cortex (DC). The rudimentary architectonics of the turtle cortical plate stands in contrast to the elaborate differentiation of the lizard cortex. PIA: pial surface; V: ventricle. HE stain. Adapted from Refs. 2 and 16. Magnification bars: $100 \mu \mathrm{m}$. 
inside-out development of the mammalian cortical plate represents an evolutionary acquisition. As maturation can be directed from outside to inside in cases when the cortical plate is radially organized (as in lizards), a second conclusion is that radial cortical plate organization, although necessary for the acquisition of the inside to outside maturation in mammals, is not sufficient. In other words, in addition to radial neuronal orientation and differentiation, other factors are needed for maturation to proceed from inside to outside. Among necessary factors are probably a larger number of neurons leading to a thicker cortical plate, and the capacity of immature neurons to migrate over large distances. This idea receives strong support from observations in mice deficient in the Cdk5 and in its p35 and p39 activators $(9,10)$. In these mice, a thin, early cortical plate develops with an almost normal radial organization, but later migrating cells cannot achieve migration over longer distances and settle at different levels in the intermediate zone, so that the maturation gradient of the cortex is still directed from outside to inside. Another example is the Tbrl mouse mutation in which the cortical plate is reasonably well organized, yet maturation is from outside to inside (23).

From comparative data and observations in mice with reeler-like and Cdk5-like phenotypes, it is tempting to propose that the cortical plate was probably poorly organized radially in stem amniotes, and that the capacity to differentiate radially evolved separately in the lineages leading to mammals and squamates. In mammals with functional control mechanisms - such as the reelin, Cdk5 and other less well-defined pathways the increase in the thickness of the cortex led to the inside-out maturation.

\section{Comparative studies on the expression of reelin in the telencephalon}

The drastic differences in cortical plate organization among different phyla, together with the observation that the gradient of cortical plate maturation is directed from outside to inside in all non-mammalian species and in reeler mice, prompted us to compare reelin expression between representatives of all amniote lineages. Reelin expression was studied in embryos from a turtle (Emys orbicularis), from lizards (several Lacerta species) and from chicks and crocodiles (2,17-19). It was not possible to obtain an embryonic brain from Sphenodon punctatus because of strict conservation procedures in New Zealand. Reelin expression was mainly studied by in situ mRNA hybridization with species-specific probes corresponding to a part of the reelin mRNA cloned by RT-PCR. A few studies of the reelin protein were also carried out using the monoclonal antibody 142 that reacts with reelin in all species studied thus far. Some preliminary studies of Dab1 mRNA expression were also performed in turtles and lizards. It is difficult to assess the level of expression using in situ hybridization as the signal depends also upon the length and the hybridization capacity of the probe. However, since reelin is expressed in olfactory mitral cells in all species studied thus far (except zebrafish), comparison of signal intensity in cortical neurons versus mitral cells gives a rough estimate of relative levels of expression. In the turtle embryonic telencephalon (Figure 4), a few heavily reelin-positive cells are present in the marginal zone, and several less intensely labeled cells are also dispersed in the cortical plate. Dab1 expression is restricted to the cortical plate and is mostly not colocalized with reelin, although reelin and Dab1 are probably co-expressed in some cells. The intensity of the reelin signal in marginal zone cells is inferior to that in the olfactory bulb. In lizards the situation is very different (Figure 5). Using anti-reelin antibodies and in situ mRNA hybridization, heavily positive cells were found in the marginal zone and in the subcortex, but not a 
single reelin-positive cell was detected in the dense cortical plate in medial and dorsal pallial areas, which contained Dab1-positive neurons. In the lateral cortex, reelin- and Dab1-positive neurons were somewhat mixed, although reelin expression seemed more diffuse than Dab1 expression, which was restricted to the dorsal aspect. At this level, some neurons may co-express reelin and Dab1, but this should be confirmed using both markers simultaneously. The pattern in lizards is unique, with heavy reelin expression in the marginal zone and subcortex, and Dab1 expression in the dense cortical plate. The reelin expression level in the marginal zone and subcortex is comparable to that in mitral cells. One may perhaps imagine that reelin defines the upper and lower borders of the dense Dab1-positive cortical plate by preventing neuronal somata from migrating in reelin-rich zones. In the crocodilian embryonic telencephalon (Figure 6), future cortical areas are less defined than in lizards, but clearly all of them contain reelin-positive cells in their marginal zone. In contrast to turtles, very few reelin-positive cells are dispersed within the cortex. Unlike lizards, crocodiles lack reelin expression in the subcortex. The level of reelin expression in marginal zone neurons is lower than or equivalent to that in the olfactory bulb. Not surprisingly, the chick telencephalon is rather similar to that of crocodiles (Figure 7). Cortical areas are, however, reduced in birds compared to crocodilians and even compared to turtles, suggesting that crocodiles are more closely related to stem archosaurs. In parallel, reelin-positive neurons are dispersed in the chick marginal zone as in crocodiles, but they are less abundant and prominent than in the crocodilian cortex. It should be added that the DVR contains some reelin- and Dab1-positive cells in all reptiles studied, which, however, have not been studied in detail since the architectonic patterns of the DVR are poorly defined in most species, except lizards and Sphenodon.

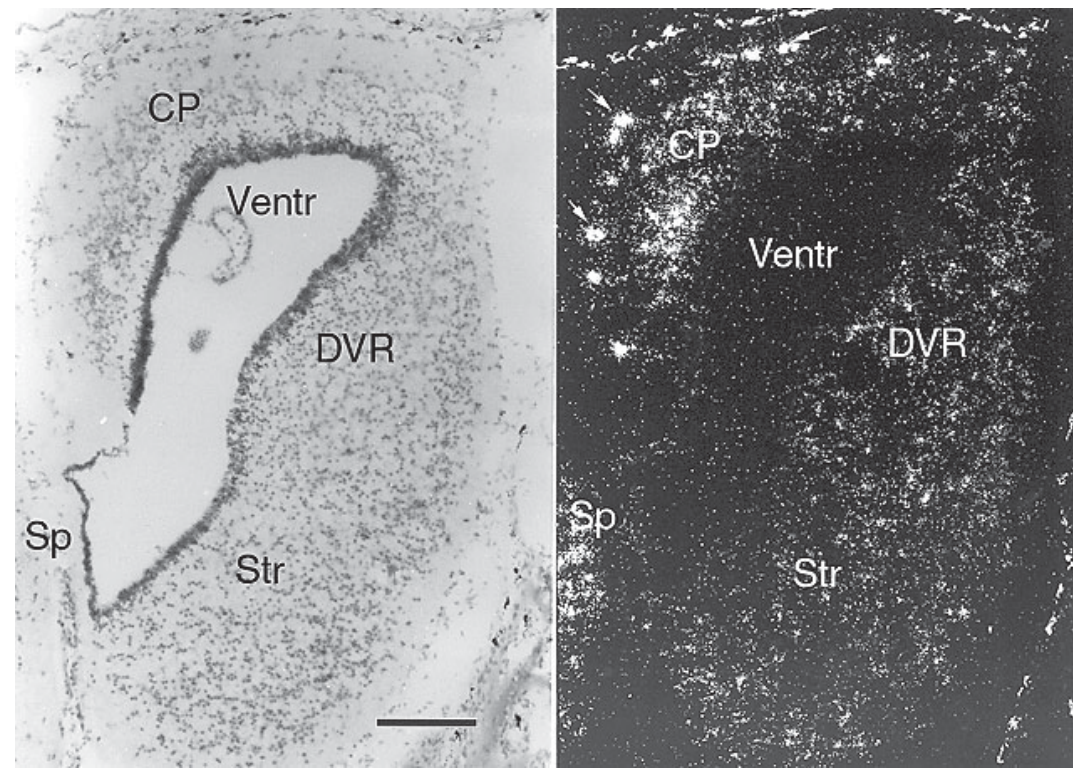

Figure 4. Reelin mRNA expression in the turtle embryonic cortex. Bright and dark field view of a coronal section through a turtle embryo (Emys orbicularis). In situ hybridization with a [33P]-labeled, species-specific reelin riboprobe. The poor laminar organization of the cortical plate (CP) in all cortical fields is evident. Reelin-positive cells are heavily labeled in the marginal zone and less intensely labeled cells are dispersed in the cortical plate. The strong darkfield signal of melanophores (arrows) is not related to probe hybridization. DVR: dorsal ventricular ridge; Sp: septum; Str: striatum; Ventr: ventricle. Adapted from Ref. 17. Magnification bar: $200 \mu \mathrm{m}$.

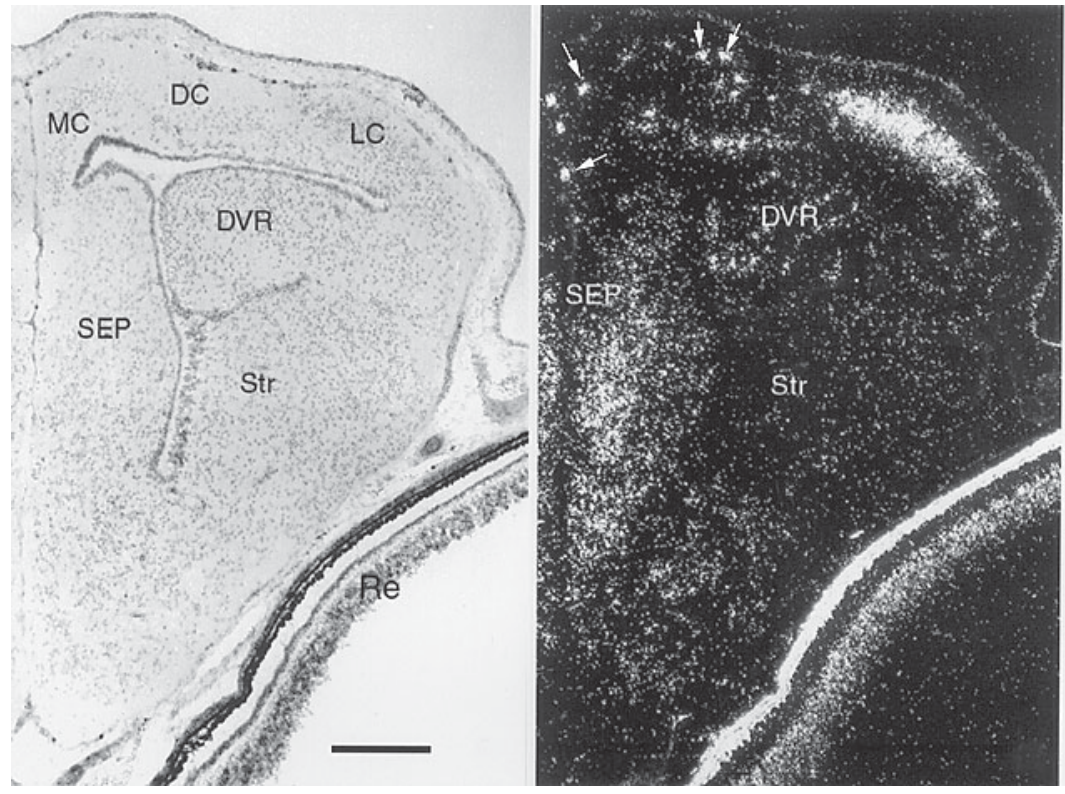

Figure 5. Reelin mRNA expression in the lizard embryonic cortex. Bright and dark field view of a coronal section through a lizard embryo (Lacerta viridis). In situ hybridization with a $\left.{ }^{33} \mathrm{P}\right]$-labeled, species-specific reelin riboprobe. The elaborate radial organization of the cortical plate in the medial (MC) and dorsal cortex (DC), and the looser architectonics of the lateral cortex (LC) are evident. Reelin-positive cells are heavily labeled in the marginal zone (arrows) and in the subcortex (not shown). DVR: dorsal ventricular ridge; SEP: septum; Str: striatum; Re: retina. Adapted from Ref. 18. Magnification bar: $200 \mu \mathrm{m}$. 


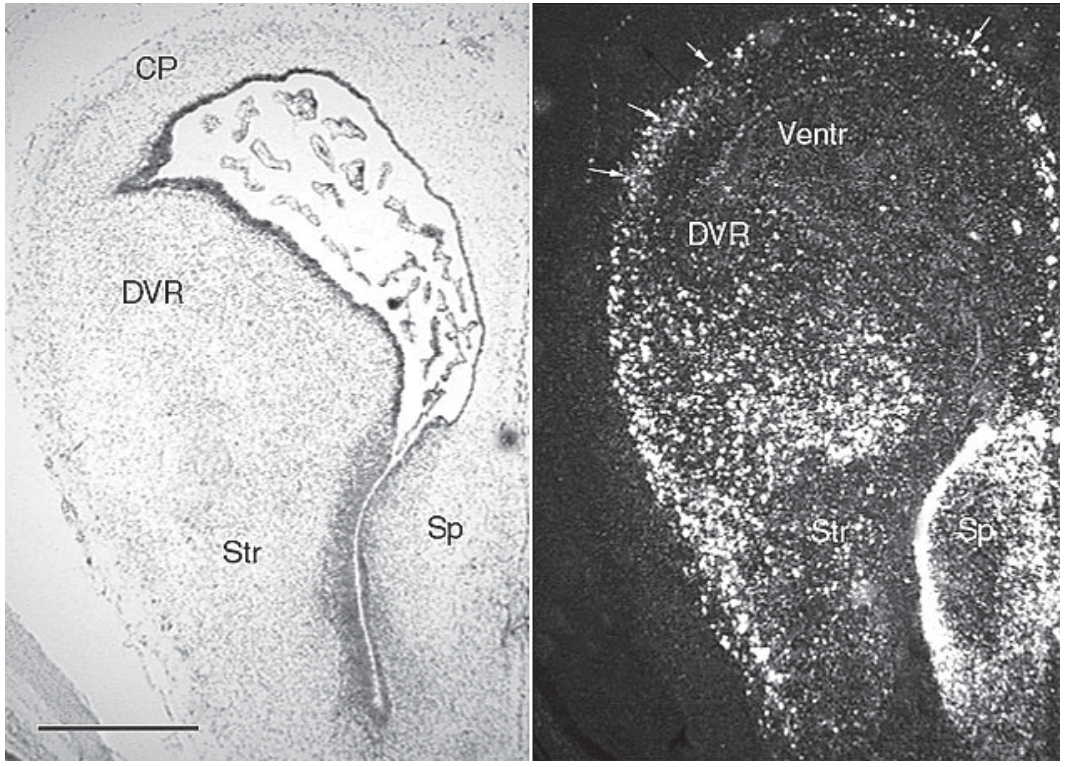

Figure 6. Reelin mRNA expression in the embryonic cortex of crocodiles. Bright and dark field view of a coronal section through a crocodile embryo. In situ hybridization with a [33P]labeled, species-specific reelin riboprobe. The cortical plate (CP) has an intermediate level of radial organization and is reelin negative, whereas the marginal zone contains reelinpositive neurons (arrows). Ventr: ventricle; Str: striatum; DVR: dorsal ventricular ridge; Sp: septum. Magnification bar: $500 \mu \mathrm{m}$.

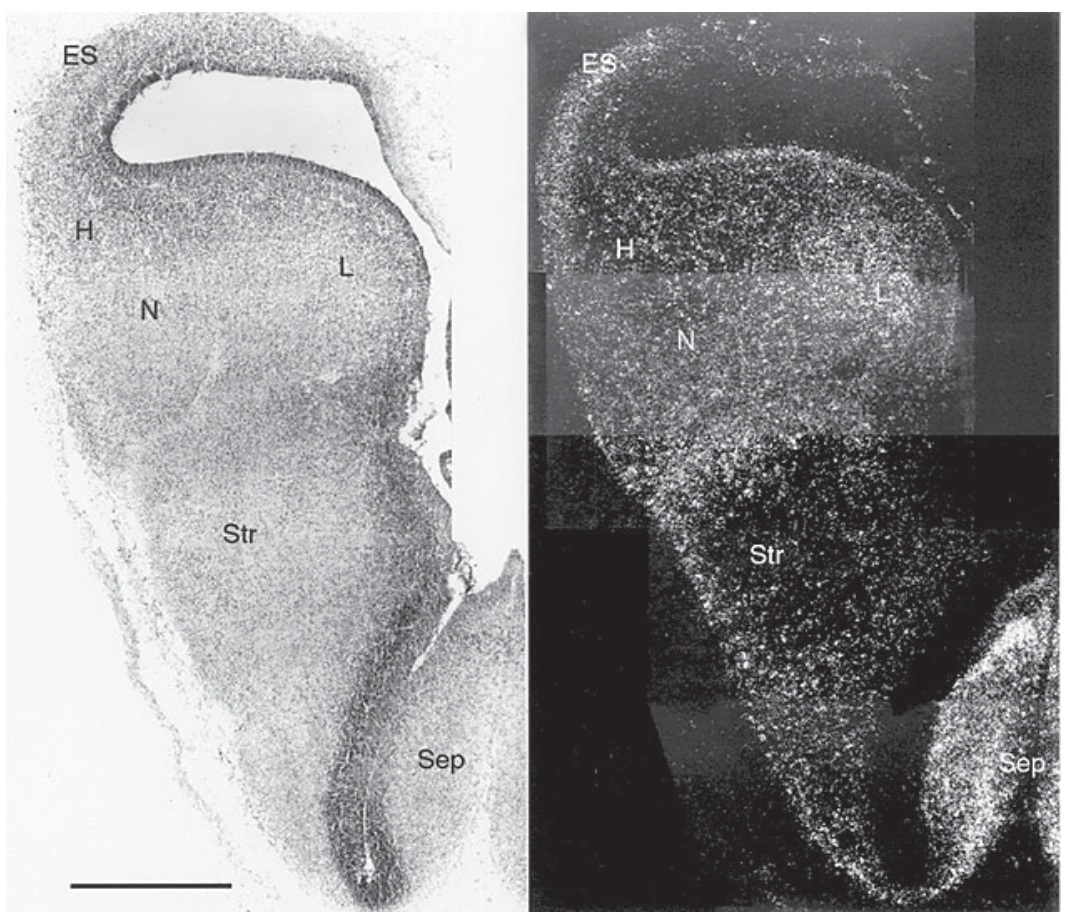

Figure 7. Reelin mRNA expression in the chick embryonic cortex. Bright and dark field view of a coronal section through a chick embryo. In situ hybridization with a [33P]-labeled, species-specific reelin riboprobe. The cortical plate is diminutive and has an intermediate level of radial organization. It is reelin negative whereas the marginal zone contains a few reelin-positive neurons. ES: eminentia sagittalis (Wülst); H: hyperstriatum; N: neostriatum; L: area "L»; Str: striatum; Sep: septum. Adapted from Ref. 19. Magnification bar: $500 \mu m$.

\section{Conclusion: A synthetic model}

Our comparative studies still contain many gaps. It would be useful to study in more detail the expression patterns of Dab1 and of the reelin receptors VLDLR and ApoER2 to confirm the expression canvas in a few other species, and particularly to analyze Sphenodon embryos. In spite of these caveats, it is reasonable to propose the following model of reelin expression and its role in cortical evolution (2). First, reelin is most probably expressed in the embryonic brain in all vertebrates, with a common pattern that includes (with some anecdotal exceptions) expression in the retina, spinal cord, reticular formation, olfactory mitral cells, cerebellar granule cells, thalamic reticular nuclei, septal nuclei and some scattered cells in the telencephalon. In stem amniotes, this common pattern of reelin expression probably included high expression in marginal zone neurons and lower expression in neurons scattered in a loosely defined cortical plate. In this loose cortical plate, most neurons expressed Dab1 and maturation proceeded from outside to inside; this pattern apparently changed little during evolution of the anapsid lineage and is still found in modern turtles. During evolution of the archosaur lineage, an increase in the number of reelin-positive neurons occurred in the marginal zone, but fewer neurons expressed reelin in the cortical plate. The cortical plate increases in thickness and neuronal content but remains poorly organized from an architectonic standpoint, and maturation still proceeds from outside to inside; this pattern is found in modern crocodilians and, to a lesser extent, in birds. A different pattern evolved in the lepidosaurian lineage, in which reelin expression is amplified not only in neurons in the marginal zone, but also in the subcortex, whereas Dab1 expression is confined to the reelin-negative cortical plate. Furthermore, in this lineage, the pattern evolved differently in various cortical areas and in 
parallel to the evolution of architectonic lamination: it is the most evident in the medial and dorsal cortex and less marked in lateral cortical fields, and intermediate in DVR areas. Cortical plate maturation proceeds from outside to inside in all areas, except in the medial cortex in which no gradient is perceived. This pattern is found to different extents in lizards, snakes and probably Sphenodon. In the three lineages above (turtles, lizards, crocodiles and birds), and thus probably in stem amniotes, the level of reelin expression in marginal zone cells was not heavily amplified and remained comparable to that observed in olfactory mitral cells. A different situation is found in mammals. Evolution of the synapsid lineage from stem amniotes is characterized by two key features. First, at an unknown stage, a spectacular amplification of reelin expression occurs in marginal zone cells, whereas the early cortical plate becomes reelin negative. Second, again at an unknown stage of cortical evolution, the outside to inside gradient of cortical plate maturation changes and becomes directed from inside to the outside. Mutations in the reelin pathway and other genes $(\mathrm{Cdk} 5, \mathrm{p} 35)$ show that the evolution of reelin expression is necessary but not sufficient for inside-outside maturation of the cortex. Clearly, a lot of work remains to be done in order to better define the molecular determinants of cortical evolution.

\section{References}

1. Raff RA (1996). The Shape of Life. Chicago University Press, Chicago, IL, USA

2. Bar I, Lambert de Rouvroit C \& Goffinet AM (2000). The evolution of cortical development. An hypothesis based on the role of the Reelin signalling pathway. Trends in Neurosciences, 23: 633-638.

3. Lambert de Rouvroit C \& Goffinet AM (1998). The reeler mouse as a model of brain development. Advances in Anatomy, Embryology and Cell Biology, 150: 1-108.

4. Rice DS \& Curran T (2001). Role of the reelin signaling pathway in central nervous system development. Annual Review of Neuroscience, 24: 1005-1039.

5. Parnavelas JG (2000). The origin and migration of cortical neurones: new vistas. Trends in Neurosciences, 23: 126-131.

6. Marin O \& Rubenstein JL (2001). A long, remarkable journey: tangential migration in the telencephalon. Nature Reviews. Neuroscience, 2: 780-790.

7. Meyer G, Soria JM, Martinez-Galan JR, Martin-Clemente B \& Fairen A (1998). Different origins and developmental histories of transient neurons in the marginal zone of the fetal and neonatal rat cortex. Journal of Comparative Neurology, 397: 439-518.

8. Meyer G, Schaaps JP, Moreau L \& Goffinet AM (2000). Embryonic and early fetal development of the human neocor- tex. Journal of Neuroscience, 20: 18581868

9. Ohshima T, Ward JM, Huh CG, Longenecker G, Veeranna Pant HC, Brady RO, Martin LJ \& Kulkarni AB (1996). Targeted disruption of the cyclin-dependent kinase 5 gene results in abnormal corticogenesis, neuronal pathology and perinatal death. Proceedings of the National Academy of Sciences, USA, 93: 11173-11178.

10. Ko J, Humbert S, Bronson RT, Takahashi S, Kulkarni AB, Li E \& Tsai LH (2001). p35 and p39 are essential for cyclin-dependent kinase 5 function during neurodevelopment. Journal of Neuroscience, 21: 6758-6767.

11. Trommssdorf M, Gotthardt M, Hiesberger T, Shelton J, Stockinger W, Nimpf J, Hammer RE, Richardon JA \& Herz J (1999). Reeler/disabled-like disruption of neuronal migration in knockout mice lacking the VLDL receptor and ApoE receptor 2. Cell, 97: 689-701.

12. Hiesberger $\mathrm{T}$, Trommssdorf $\mathrm{M}$, Howell BW, Goffinet AM, Mumby MC, Cooper JA \& Herz J (1999). Direct binding of Reelin to VLDL receptor and ApoE receptor 2 induces tyrosine phosphorylation of disabled-1 and modulates tau phosphorylation. Neuron, 24: 481-489.

13. Howell BW, Hawkes R, Soriano P \& Cooper JA (1997). Neuronal position in the developing brain is regulated by mouse disabled-1. Nature, 389: 733-737.

14. Ware ML, Fox JW, Davis NM, Lambert de Rouvroit C, Russo C, Chua Jr SC, Goffinet AM \& Walsh CA (1997). Aberrant splicing of a mouse disabled homolog, mDab1, in the scrambler mouse. Neuron, 19: 239249

15. Howell BW, Herrick TM, Hildebrand JD, Zhang Y \& Cooper JA (2000). Dab1 tyrosine phosphorylation sites relay positional signals during mouse brain development. Current Biology, 10: 877-885.

16. Goffinet AM (1983). The embryonic development of the cortical plate in reptiles: a comparative study in Emys orbicularis and Lacerta agilis. Journal of Comparative Neurology, 215: 437-452.

17. Bernier B, Bar I, Pieau C, Lambert de Rouvroit C \& Goffinet AM (1999). Reelin mRNA expression during embryonic brain development in the turtle. Journal of Comparative Neurology, 413: 463-479.

18. Goffinet AM, Bar I, Bernier B, Trujillo C, Raynaud A \& Meyer G (1999). Reelin expression during embryonic brain development in lacertilian lizards. Journal of Comparative Neurology, 414: 533-550.

19. Bernier B, Bar I, D'Arcangelo G, Curran T \& Goffinet AM (2000). Reelin mRNA expression during embryonic brain development in the chick. Journal of Comparative Neurology, 422: 448-463.

20. Northcutt RG (1981). Evolution of the tel- 
encephalon in non-mammals. Annual Review of Neuroscience, 4: 301-350.

21. Goffinet AM, Daumerie Ch, Langerwerf B \& Pieau C (1986). Neurogenesis in reptilian cortical structures: ${ }^{3} \mathrm{H}$ thymidine autoradiographic analysis. Journal of Comparative Neurology, 243: 106-116.
22. Tsai HM, Garber GB \& Larramendi LMH (1981). Thymidine autoradiographic analysis of telencephalic histogenesis in the chick embryo: I. Neuronal birthdates of telencephalic compartments in situ. Journal of Comparative Neurology, 198: 275292.
23. Hevner RF, Shi L, Justice N, Hsueh $Y$, Sheng M, Smiga S, Bulfone A, Goffinet AM, Campagnoni AT \& Rubenstein JL (2001). Tbr1 regulates differentiation of the preplate and layer 6. Neuron, 29: 353366 . 